\title{
Characterization of Phase and Emulsion Behavior, Surfactant Retention, and Oil Recovery for Novel Alcohol Ethoxycarboxylate Surfactants
}

\author{
Semi-Annual Report \\ October 1, 1997 - April 1, 1998 \\ By
Lebone T. Moeti; Ramanathan Sampath
}

Work Performed Under Contract No.: DE-FG26-97FT97278

For

U.S. Department of Energy

Office of Fossil Energy

Federal Energy Technology Center

P.O. Box 880

Morgantown, West Virginia 26507-0880

By

Department of Engineering

Clark Atlanta University

Atlanta, Georgia 30314 


\section{Disclaimer}

This report was prepared as an account of work sponsored by an agency of the United States Government. Neither the United States Government nor any agency thereof, nor any of their employees, makes any warranty, express or implied, or assumes any legal liability or responsibility for the accuracy, completeness, or usefulness of any information, apparatus, product, or process disclosed, or represents that its use would not infringe privately owned rights. Reference herein to any specific commercial product, process, or service by trade

name, trademark, manufacturer, or otherwise does not necessarily constitute or imply its endorsement, recommendation, or favoring by the United States Government or any agency thereof. The views and opinions of authors expressed herein do not necessarily state or reflect those of the United States Government or any agency thereof. 
Characterization of Phase and Emulsion Behavior, Surfactant Retention, and Oil Recovery for Novel Alcohol Ethoxycarboxylate Surfactants

Semi-Annual Progress Report

For the Period October 01, 1997 to April 01, 1998

Lebone T. Moeti (PI) and Ramanathan Sampath

May 1998

Grant No. DE-FG26-97FT97278--01

For

AAD Document Control

U.S. Department of Energy

Federal Energy Technology Center

P.O. Box 10940, MS 921-143

Pittsburgh, PA 15236-0940

By

Department of Engineering

Clark Atlanta University

Atlanta, GA 30314 
Characterization of Phase and Emulsion Behavior, Surfactant Retention, and Oil Recovery for Novel Alcohol Ethoxycarboxylate Surfactants

\begin{abstract}
This semi-annual technical progress report describes work performed at Clark Atlanta University under DOE Grant No. DE-FG26-97FT97278 during the period October 01, 1997 to April 01, 1998 which covers the first six months of the project. During this reporting period, laboratory space to set up the surfactant characterization measurement system in the Research Science Center was made available. A Ph.D. student in Chemistry was identified and is supported as a Graduate Research Assistant in this project. Her contribution towards this project will form her Ph.D. thesis. The test matrix to perform salinity and temperature scans was established. Supply requests to obtain refined hydrocarbon, surfactant, and crude were processed and supplies obtained. A temperature bath with a control unit to perform temperature scans was obtained on loan from Federal Energy Technology Center, Morgantown, WV. The setting up of the temperature control unit, and associated chiller with water circulation lines is in progress. Tests were conducted on several hybrid surfactants to identify the best surfactants for future experimental work that yield almost equal volumes of top, middle, and bottom phases when mixed with oil and water. The student reviewed the current literature in the subject area, and modeling efforts that were established in previous studies to predict electrical conductivities and inversion phenomena. These activities resulted in one published conference paper, and one student poster paper during this reporting period.
\end{abstract}




\section{TABLE OF CONTENTS}

page

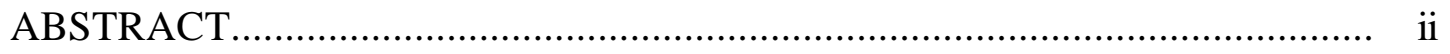

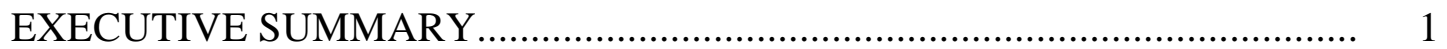

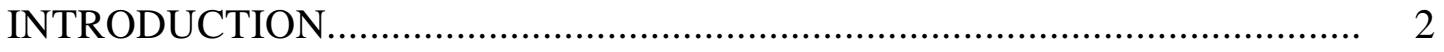

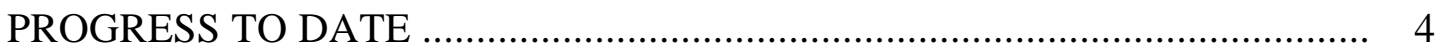

WORK PERFORMED DURING THIS PERIOD.......................................... 5

OUTCOMES OF THIS PERIOD................................................................. 6

PLANS FOR THE NEXT REPORTING PERIOD............................................ 6

SUMMARY AND CONCLUSIONS.............................................................. 7

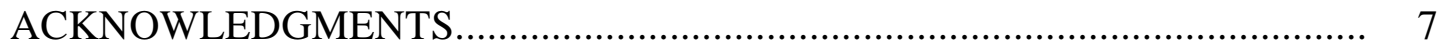

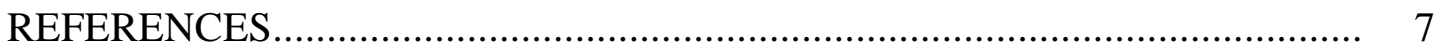




\section{EXECUTIVE SUMMARY}

In this semi-annual report, the work performed under DOE Grant No. DE-FG26-97FT97278 during the period October 01, 1997 to April 01, 1998 which covers the first six months of the project is described and the major accomplishments are highlighted summarizing the most important research results.

Many surfactants will simultaneously form three coexisting liquid phases when mixed with oil and water within a well defined salinity and temperature interval. At the mean temperature of this interval one finds--for thermodynamic reasons--a maximum of the mutual solubility between water and oil. The middle phase, which contains the greatest concentration of surfactant, is called a microemulsion. Typically the microemulsion reduces the interfacial tension between oil and water by about three or four orders of magnitude. These ultralow tensions allow the oil-rich (top) phase to be pushed through porous media by the aqueous (bottom) phase, and the three liquid phases flow as macroemulsions. The microemulsion phase can also form two-phase, or three-phase, macroemulsion structures or morphologies when mixed with either one, or both, of the other two phases, depending on the temperature, relative volumes of the phases, and other factors. Formation of a wrong morphology or inversion from the desired morphology to the wrong morphology is also possible. Investigation of these morphologies, when they occur, and their flow through porous media are of considerable interest in Enhanced Oil Recovery (EOR).

Selection of effective surfactants and a better understanding of the formation of their emulsions with crude oils are of paramount importantance for progress towards EOR. Alcohol ethoxycarboxylates (AEC) are novel and are hybrids exhibiting both ionic (carboxylate) and nonionic (ethoxy) characteristics depending on the conditions of the applications. These surfactants have not yet been tested for their suitability in enhanced oil recovery. The objectives of this proposal are to characterize the phase and emulsion behavior, and surfactant retention and oil recovery capabilities of novel alcohol ethoxycarboxylate surfactants. The successful accomplishment of the objectives will provide a detailed and unique database for alcohol ethoxycarboxylate surfactants for oil recovery. If the surfactant is found effective, the database would be of immense value for developing costeffective surfactant flooding processes.

Presently work is in progress at the EOR Laboratory, Clark Atlanta University (CAU), to characterize phase and emulsion behavior for alcohol ethoxycarboxylate surfactants. Temperature and salinity scans are being performed at CAU to identify the optimal salinity and temperature, and the temperature and salinity intervals in which all three phases coexist. Core flooding measurements will be conducted by our industrial partner, Surtek, $\mathrm{CO}$, to characterize surfactant retention and oil recovery. 


\section{INTRODUCTION}

The Department of Energy has been sponsoring fundamental and applied research in the enhanced oil recovery area. Recently, the DOE 's National Petroleum Technology Office, Tulsa, Oklahoma, has been interested in research focussing on the use of novel surfactants for effective oil recovery. If better surfactants can be found, the potential for surfactant flooding is great.

After an oil well loses its self flow (primary recovery by natural forces), and secondary flow (secondary recovery by pressurization using water flood and gas), approximately $2 / 3$ of the original oil remains in the reservoir. This accounts for an estimated 327 billion barrels in the United States. Much of the remaining oil can be collected by enhanced oil recovery techniques such as surfactant flooding. Effective emulsifying surfactants and a better understanding of the formation of their emulsions with the crude are of paramount importance to economically recover the abundant residual oil in reservoirs.

Mixtures of water, oils, amphiphiles, and salt may separate into three coexisting liquid phases within a well defined temperature interval, the mean temperature of which may depend sensitively but systematically on the nature of the oil and the amphiphile and on the salt concentration. At the mean temperature of this interval one finds--for thermodynamic reasons--a maximum of the mutual solubility between water and oil and a minimum of the interfacial tension between the aqueous and the oil-rich phase. Both of these properties are of considerable interest for both research and industrial application.

Emulsions and other fluid-fluid dispersions have long been used in many different commercial products and processes, such as liquid-liquid extractions, foods, medicines, paints, cosmetics, and the production and transport of petroleum. One of the most novel applications is the use of dispersions of supercritical $\mathrm{CO}_{2}$ to improve oil recoveries from miscible flood enhanced oil recovery [1]. Each of these applications depends on the formation of a dispersion of the desired morphology, for example, an "oil-in-water" or a "water-in-oil" emulsion. Formation of the "wrong" morphology or inversion from the desired morphology to the "wrong" morphology causes the product or process to fail.

Many, if not most, of the two-phase emulsions commonly encountered at various temperatures in systems of nonionic surfactant, oil, and water form in systems that also can form [2] triconjugate oil-rich top phase (T), water-rich bottom phase (B), and middle-phase microemulsion (M). For such systems, two-phase emulsions may form in any of the various two-phase regions [3-4] that surround a stack of tie triangles in the triangular-prismatic phase diagram. For temperatures between lower and upper critical points $\mathrm{T}_{\mathrm{lc}}$ and $\mathrm{T}_{\mathrm{uc}}$--the range over which phases $\mathrm{T}, \mathrm{M}$, and $\mathrm{B}$ coexist-there are three two-phase regions and thus six nonmultiple, two phase emulsion morphologies [5]. For such systems the plotting of phase boundaries and of boundaries between different emulsion morphologies in accordance with the phase rule introduces a rigorous way of showing how the occurrence of each of the six two-phase morphologies depends on temperature and composition. For the limiting tie lines (i.e., the sides of the tie triangle), where the three-phase and two-phase regions 
meet, the six two-phase morphologies are formed by the triconjugate phases taken pairwise: T/M, $\mathrm{M} / \mathrm{T} ; \mathrm{B} / \mathrm{T}, \mathrm{T} / \mathrm{B}$; and $\mathrm{M} / \mathrm{B}, \mathrm{B} / \mathrm{M}[6]$.

One of the widely observed phenomena of emulsion inversion is inversion hysteresis [7]. For example, the phase volume fractions at which the inversions $\mathrm{A} / \mathrm{B}$ to $\mathrm{B} / \mathrm{A}$ and $\mathrm{B} / \mathrm{A}$ to $\mathrm{A} / \mathrm{B}$ occur are somewhat different. If the pair of phase volume fraction points at which the pair of conjugate inversions occur are measured at different temperatures, the resulting measurements form a pair of inversion hysteresis lines in phase volume fraction-temperature space. The fractional phase volume at which inversion occurs is believed to depend on many different factors, such as the temperature, structure and concentration of the emulsifying amphiphile, salinity, and "oil" composition. The factors that control dispersion morphology and inversion are now well understood [6]. Qualitatively, dispersion inversion has long seemed to be a catastrophic event. The properties of an $A / B$ (A-in-B) dispersion are very different from the properties of a B/A (B-in-A) dispersion, and the inversion from one morphology to the other is often abrupt and irreversible. Inversion is marked by a sudden change in the physical properties (e.g., electrical conductivity) of the dispersion, indicating an abrupt change in the structure of the dispersion [6]. Smith et al. [6,8-10] demonstrated for several oil/water/surfactant systems that elementary catastrophe theory provides a unifying framework to explain these phenomena in systems of variable oil/water ratio and amphiphile concentration at constant temperature and pressure. Smith et al. [2] hypothesized that wherever a phase critical point occurs, there will be a "critical point" for dispersion inversion, also; that is, pairs of dispersion inversion hysteresis lines meet at a point, and this point coincides with the critical point for the two phases of the dispersion.

Recently, experiments were performed [6] for the surfactant/oil/water system $\mathrm{C}_{6} \mathrm{H}_{13}\left(\mathrm{OC}_{2} \mathrm{H}_{4}\right)_{2} \mathrm{OH} / \mathrm{n}$-tetradecane/aqueous $10 \mathrm{~mm} \mathrm{NaCl}$ at temperatures from $298 \mathrm{~K}$ down to $285 \mathrm{~K}$, near the lower critical end-point temperature $\left(\mathrm{T}_{\mathrm{lc}}=283.6 \mathrm{~K}\right)$. Morphologies and phase volume fractions at which inversion occurred were determined for (macro)emulsions formed by the middlephase microemulsion (M) and water-rich bottom phase (B) by means of electrical conductivity measurements. The $\mathrm{M} / \mathrm{B}$ and $\mathrm{B} / \mathrm{M}$ morphologies and their inversion hysteresis lines were found to conform to the dispersion morphology diagram previously postulated by Smith et al. [2]; that is, within experimental uncertainties, the two emulsion inversion lines in phase volume-temperature space met at a "critical point"' that coincided with the lower critical end point for the phases.

The phase behavior, interfacial tension, and solution physical parameters only define a single interface in the oil recovery process, the water-oil interface. In an oil and water filled reservoir system, two other interfaces exist, the oil-rock and water-rock interface. The effect of these two interfaces on the oil recovery process are just as important, if not more important, than the water-oil interface [11-14]. Linear and radial corefloods are used to test the effect of the two rock interfaces on the oil recovery potential of the surfactant systems. Linear corefloods provide adsorption coefficients of chemicals onto the rock surface and define fluid rheology as the ability of the solution to flow through porous media. Radial corefloods to estimate oil recovery potential are preferable to linear corefloods for a number of reasons [11-16]. The pore volume of a radial core is greater than that of a linear core, making measurement of the injected and produced fluids volumes more accurate. 
The flow patterns in a radial core allow expansion of the interface between the injected surfactant and the fluid in the core to occur in a similar manner as in a vertical well in the field. When fractional pore volumes of chemical are injected, chemical banks thin in a manner analogous to a vertical well in the field allowing dispersion, dilution, and other potentially deleterious effects to occur.

The Shell Chemical Company produces NEODOL ethoxylates that are non-ionic surfactants. These surfactants are relatively inexpensive. A number of them have been tried in oil recovery. NEODOX Alcohol Ethoxycarboxylates (AEC) have recently been produced by the Shell Chemical Company by an oxidative reaction of alcohol ethoxylate with air or oxygen and have not yeen been tested for their suitability in oil recovery. These surfactants are $>90 \%$ purity. These novel surfactants are hybrid exhibiting both ionic (carboxylate) and non-ionic (ethoxy) characteristics depending on the conditions of the applications. They exhibit good alkaline stability, electrolyte tolerance, good emulsification, and temperature stability that make them highly suitable for enhanced oil recovery. The ionic part of these hybrid surfactants would make them adsorb less on rocks. Emulsions formed by these surfactants can easily be broken by adjusting the $\mathrm{pH}$ in order to recycle the oil, water, and the surfactant. These surfactants are novel and Shell does not have technical data such as salinity scans, temperature-surfactant concentration plots, and adsorption coefficient for these surfactants.

This project seeks to characterize novel alcohol ethoxycarboxylate (AEC) surfactants that are commercially available. Detailed information on optimal salinity, temperature, adsorption coefficient, oil recovery, and emulsion morphologies for these surfactants is needed to evaluate their performance in terms of cost-effectiveness, adsorptivity, and oil recovery efficiency in flooding processes. The specific objectives are:

1) Perform salinity and temperature scans scans to obtain optimal salinity and temperature at which all three phases coexist.

2) Perform emulsion morphology and coreflooding experiments for the oil/water/surfactant system that gives the best results in objective 1 .

Experiments and analyses are being carried out to meet the project objectives. Objectives 1 and phase work will be accomplished by CAU. Coreflooding experiments will be accomplished by Surtek, our industrial partner in this project. The successful accomplishment of the objectives will provide a detailed and unique database for ethoxycarboxylate surfactants for oil recovery. If the surfactant is found effective, the database would be of immense value for developing cost-effective surfactant flooding processes.

\section{PROGRESS TO DATE}

The hybrid surfactant research program discussed above began at Clark Atlanta University in October 1997. Laboratory space to set up the proposed surfactant characterization measurement system in the Research Science Center was made available. A Ph.D. student in Chemistry was identified and is supported as a Graduate Research Assistant in this project. Her contribution 


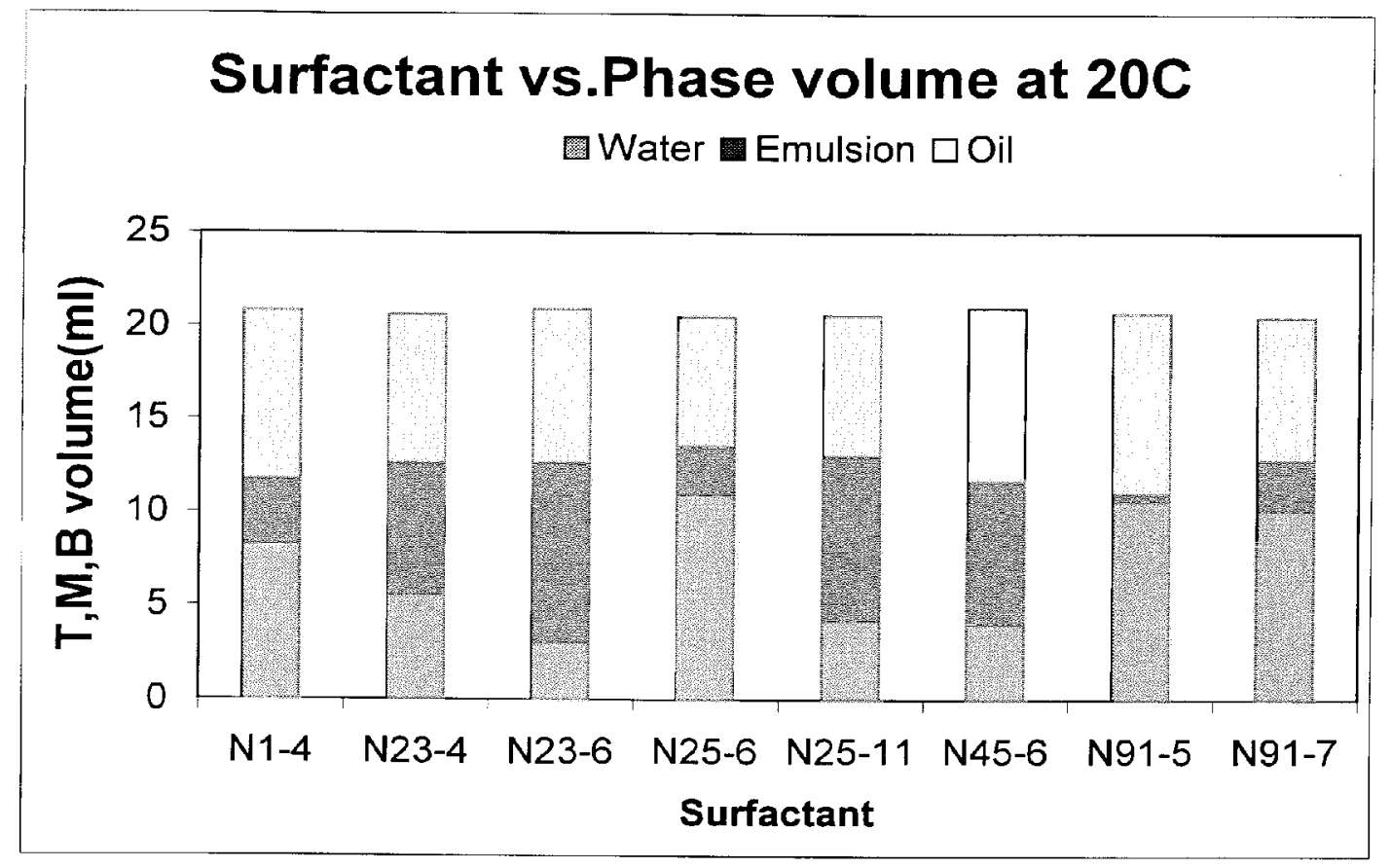

towards this project will form her Ph.D. thesis. The test matrix to perform salinity and temperature scans was established. Supply requests to obtain refined hydrocarbon, surfactant, and crude were processed. A temperature bath with a control unit to perform temperature scans was obtained on loan from Federal Energy Technology Center, Morgantown, WV. The setting up of the temperature control unit, and associated chiller with water circulation lines is in progress. Tests were conducted on several hybrid surfacatants to identify the best surfactants for future experimental work that yield almost equal volumes of top, middle, and bottom phases when mixed with oil and water. The student reviewed the current literature in the subject area, and modeling efforts that were established in previous studies to predict electrical conductivities and inversion phenomena. This work aided in publishing one conference paper, and one student poster paper during this reporting period.

\section{WORK PERFORMED DURING THIS PERIOD}

Ms. Junli Chen, a Ph.D. student from the Department of Chemistry, CAU, was identified and supported as a Graduate Research Assistant in this project. Her contribution towards this project will form her dissertation. Junli reviewed the current literature in the subject area [1-19], and modeling efforts that were established in previous studies [6,17-19] to predict electrical conductivities and inversion phenomena.

Typical NEODOX AEC's are: NEODOX 1-4, NEODOX 23-4, NEODOX 23-6, NEODOX 25-6, NEODOX 25-11, NEODOX 45-6, NEODOX 91-5, and NEODOX 91-7. These surfactants differ in critical micelle concentration, foaming and wetting time. Tests are in progress on these surfactants to identify the best surfactants for future experimental work that yield the best proportion 
in volume for top, middle, and bottom phases when mixed with oil and water. Results of one such test conducted at $20 \mathrm{EC}$ are shown in Figure 1. It can be seen that NEODOX 23-4 gives the best quantity of all the three phases when mixed with oil and water. Experiments were initiated and trial runs for salinty scans for various salt concentrations were performed. These activities resulted in a technical paper and a student poster paper that were presented at the Sixth Annual DOE/HBCU/MI/Industry Technology Transfer meeting, April 27-29, Ocean City, MD.

More tests at several other temperatures $(25,30,35$, and 40 EC) to select the best NEODOX surfactant are in progress. Following the selection, temperature and salinity scans will be performed at CAU to identify the optimal salinity and temperature, and the temperature and salinity intervals in which all three phases coexist for this surfactant. About 10 samples of equal volume of crude and water with initially $2 \%$ concentration of surfactant will be tested for optimal salinity by varying the salinity with $\mathrm{NaCl}$ from 1 to $10 \%$, or greater. The temperature of the water bath in these experiments will be set at 25, 30, and $35 \mathrm{EC}$. Following the salinity experiments, measurements will be made with zero salinity or $10 \mathrm{~mm} \mathrm{NaCl}$ in water for various surfactant concentrations. The small salt concentration may be used to improve the sensitivity and accuracy of the conductivity measurements by increasing the conductivity differences between the conjugate phases of the emulsions. The resulting temperature vs. surfactant concentration plot will yield a typical alpha shape curve that will demonstrate the existence of 1,2 , or 3 phases in the system. The best oil/water/surfactant system defined by the above phase work will then be studied for core flooding, and emulsion morphologies. Core flooding measurements will be conducted by our industrial partner, Surtek, CO, to characterize surfactant retention and oil recovery. Measurements for emulsion morphologies will be performed by CAU. Briefly, electrical conductivities will be measured for top/bottom, top/middle, and middle/bottom phases that form the sides of the tie triangle diagram by mixing measured volumes of the pre-equilibrated phases.

\section{OUTCOMES OF THIS PERIOD}

1. Chen, J., Sampath, R., Moeti, L., and Smith, D., Investigation of Phase and Emulsion Behavior for Novel Alcohol Ethoxycarboxylate Surfactants, Technology Transfer Session, Historically Black Colleges/Universities and Other Minority Institutions Annual Symposium, April 28-29, 1998, Ocean City, MD.

2. Sampath, R., Moeti, L., Smith, D., and Pitts, M., Characterization of Surfactants for Enhanced Oil Recovery, Technology Transfer Session, Historically Black Colleges/Universities and Other Minority Institutions Annual Symposium, April 28-29, 1998, Ocean City, MD.

\section{PLANS FOR THE NEXT REPORTING PERIOD}

Salinity and temperature scans are scheduled to be completed within the next reporting period. 


\section{SUMMARY AND CONCLUSIONS}

The project is progressing well. A Ph.D. student was identified and literature were reviewed. Experiments on several hybrid surfactants were performed to identify a suitable surfactant for the project. These activities resulted in several papers that were presented in a conference. Experimental set up for salinity scans was complete and salinity scans are in progress.

\section{ACKNOWLEDGMENTS}

This work is supported under FETC/DOE grant No. DE-FG26-97FT97278. Technical discussions provided by Dr. Jerry Casteel, National Petroleum Technology Office, Tulsa, Oklahoma are gratefully acknowledged.

\section{REFERENCES}

1. Duane H. Smith, Editor. Surfactant-Based Mobility Control: Progress in Miscible-Flood Enhanced Oil Recovery (American Chemical Society, Washington, DC, 1988).

2. Duane H. Smith and K. H. Lim, "Morphology and Inversions of Two Fluids in Systems of Three and Four Thermodynamic Dimension," J. Phys. Chem. 94, 3746-52 (1990).

3. Kunieda, H. and Friberg, S. E., Bull. Chem. Soc. Jpn. 1981, 54, 1010.

4. Duane H. Smith, "The Role of Critical Points in HLB and the Phase Inversion Temperature, Evidence from the Cyclohexane/ Water/ i- $\mathrm{C}_{9} \mathrm{H}_{19} \mathrm{C}_{6} \mathrm{H}_{4}\left(\mathrm{OCH}_{2} \mathrm{CH}_{2}\right)_{9.2} \mathrm{OH}--$ Temperature Trigonal Prismatic Diagram," J. Colloid Interface Sci. 108, 471 (1985).

5. Duane H. Smith, "Comparison of Emulsions with the Phase Diagrams of the Systems in which They Form" in Microemulsions, H. L. Rosano and M. Clausse, Eds. (Marcel Dekker, New York, 1987).

6. Duane H. Smith, Ramanathan Sampath, and Dady B. Dadyburjor, "Temperature-Dependent Inversion Hysteresis Lines for Emulsions of Middle and Bottom Phases of the System $\mathrm{C}_{6} \mathrm{H}_{13}\left(\mathrm{OC}_{2} \mathrm{H}_{4}\right)_{2} \mathrm{OH} / \mathrm{n}$-Tetradecane/'Water'," J. Phys. Chem. 100, 17558-62 (1996).

7. Becher, P., J. Soc. Cosmetic Chem. 1958, 9, 141.

8. Duane H. Smith and K.-H. Lim, "An Experimental Test of Catastrophe and Critical-Scaling Theories of Emulsion Inversion," Langmuir 6, 1071 (1990).

9. K.-H. Lim and Duane H. Smith, "Experimental Test of Catastrophe Theory in Polar Coordinates: Emulsion Inversion for the Ethanol/Benzene/ Water System," J. Colloid Interface Sci. 142, 278-90 (1991). 
10. Duane H. Smith, G. L. Covatch, and K.-H. Lim, "Morphologies and Inversions of Emulsions of Conjugate Microemulsion and Oleic Phases in an Amphiphile/Oil/ Water System between Its Critical Endpoint Temperatures," Langmuir 7, 1585 (1991).

11. Clark, S. R., Pitts, M. J. and Smith, S. M.: "Design and Application of an AlkalineSurfactant-Polymer Recovery System to the West Kiehl Field," (1993), SPE Advanced Technology Series, Vol 1, pages 172-179.

12. Manji, K.H. and Stasiuk, B. W.: "Design Considerations for Dome's David Alkali/Polymer Flood," Can. J. Pet. Tech., (May-June 1988), Vol. 27, pages 49-54.

13. Pitts, M. J., Surkalo, H. and Wyatt, K.: "Design and Field Implementation of Alkaline-Surfactant-Polymer Chemical Enhanced Oil Recovery Systems," proceedings of the 1995 UNITAR International Conference on Heavy Crude and Tar Sands, Houston, Texas, February 12-16, 1995.

14. Lin, F. J., Besserer, G. J., and Pitts, M. A.: "Laboratory Evaluation of Cross-linked Polymer and Alkaline-Surfactant-Polymer Flood," (1987), Can. J. Pet. Tech., Vol. 35 (Nov.-Dec.).

15. Earlougher, R. C. Jr., O'Neal, J. E., and Surkalo, H.: Micellar Solution Flooding: Field Test Results and Process Improvements," SPE 5337, presented at the Rocky Mountain Regional Meeting, April 7-9, 1975.

16. Davis, J. A., Jr. and Jones, S. C.: "Displacement Mechanisms of Micellar Solutions," J. Pet. Tech., (Feb 1973), pages 186-194: Trans AIME, vol 243.

17. Johnson, G. K., A Study of Three-Phase Emulsion Behavior, PhD Dissertation, 1993, West Virginia University, Morgantown, WV.

18. G. K. Johnson, D. Dadyburjor, and Duane H. Smith, "Electrical Conductivities of ThreePhase emulsions. Part 2," Langmuir 10, 2523-27 (1994).

19. Duane H. Smith, G. K. Johnson, Y. C. Wang, and K.-H. Lim, "Electrical Conductivities of Three-Phase Emulsions. Part 1," Langmuir 10, 2516-22 (1994). 